\title{
Use of Okadaic Acid to Identify Relevant Phosphoepitopes in Pathology: A Focus on Neurodegeneration
}

\author{
Miguel Medina ${ }^{1}$, Jesús Avila ${ }^{1,2, *}$ and Nieves Villanueva ${ }^{3}$ \\ 1 CIBERNED (Center for Networked Biomedical Research in Neurodegenerative Diseases), \\ Valderrebollo 5, Madrid 28041, Spain; E-Mail: mmedina@ciberned.es \\ 2 Center of Molecular Biology “Severo Ochoa” CSIC-UAM, Nicolás Cabrera 1, Madrid 28049, Spain \\ 3 National Center of Microbiology (CNM), Carlos III Institute of Health (ISCIII), Crta. \\ Majadahonda-Pozuelo km 2, Majadahonda, Madrid 28220, Spain; E-Mail: nvilla@isciii.es \\ * Author to whom correspondence should be addressed; E-Mail: javila@cbm.uam.es; \\ Tel.: +34-91-196-4803; Fax: +34-91-196-4715.
}

Received: 18 March 2013; in revised form: 2 April 2013 / Accepted: 16 April 2013 /

Published: 21 May 2013

\begin{abstract}
Protein phosphorylation is involved in the regulation of a wide variety of physiological processes and is the result of a balance between protein kinase and phosphatase activities. Biologically active marine derived compounds have been shown to represent an interesting source of novel compounds that could modify that balance. Among them, the marine toxin and tumor promoter, okadaic acid (OA), has been shown as an inhibitor of two of the main cytosolic, broad-specificity protein phosphatases, PP1 and PP2A, thus providing an excellent cell-permeable probe for examining the role of protein phosphorylation, and $\mathrm{PP} 1$ and $\mathrm{PP} 2 \mathrm{~A}$ in particular, in any physiological or pathological process. In the present work, we review the use of okadaic acid to identify specific phosphoepitopes mainly in proteins relevant for neurodegeneration. We will specifically highlight those cases of highly dynamic phosphorylation-dephosphorylation events and the ability of OA to block the high turnover phosphorylation, thus allowing the detection of modified residues that could be otherwise difficult to identify. Finally, its effect on tau hyperhosphorylation and its relevance in neurodegenerative pathologies such as Alzheimer's disease and related dementia will be discussed.
\end{abstract}

Keywords: Alzheimer; GSK-3; kinases; neurodegeneration; okadaic acid; phosphatases; phosphorylation; PP2A; tangles; tau 


\section{Introduction}

Okadaic acid is a lipophilic natural compound originally isolated from the marine black sponges Halichondria okadaii and Halichondria melanodocia [1] and it was subsequently shown to be produced by several marine dinoflagellates belonging to the genera Dinophysis and Prorocentrum [2,3]. This polyether fatty acid compound is almost exclusively accumulated in the mussel digestive gland and consumption of these mollusks might lead to a syndrome in humans known as diarrheic shellfish poisoning (DSP) due to the toxic effects of OA and its analogs, collectively known as dinophysistoxins [4-6].

Due to the severe gastrointestinal symptoms associated to DSP, OA is primarily considered to be an enterotoxin [7,8], causing epithelial damage and fluid accumulation in the gastrointestinal tract that eventually, at high doses, may lead to death. However, low oral doses have also been shown to lead to systemic immunotoxicity in mice [9] and in vivo studies in mice, have reported OA distribution and excretion after oral administration as well as morpho-functional changes in several organs targeted by the toxin [10]. Thus, the target organ and the severity of OA-induced toxic effects depend on the dose and the route of administration [11]. For instance, when administered intravenously, OA is highly hepatotoxic with undetectable effects on the intestine but also has an impact on cytoskeletal elements at sub-lethal doses [12]; or when applied to mouse skin OA causes severe irritation. In addition, Halichondria okadaii crude extracts had already been shown in the 1970s to show remarkable cytotoxic activity. Several polyethers, including OA and halichondrins, were later isolated and shown to be responsible for the anti-mitotic activity associated with the crude natural extracts [13]. Finally, 25 years after the first report of tumor promotion by OA in [14], it is now well established that the toxin is functionally a potent tumor promoter in various organs, including skin, stomach and liver $[15,16]$.

\section{Molecular and Cellular Effects}

OA was first identified as a potent phosphatase inhibitor about a quarter of century ago in a pioneer study [17] and its toxicity has since been generally attributed to its effect on cellular phosphatases, although some authors have recently put a causal effect into question [18]. OA is a potent inhibitor of two major Ser/Thr protein phosphatases present in mammalian cells, PP2A and PP1, with $\mathrm{IC}_{50}$ values of $0.2 \mathrm{nM}$ and $20 \mathrm{nM}$, respectively, but potently inhibits other phosphatases as well, such as PP4 and PP5 $[19,20]$. In addition OA it is also able to inhibit, albeit to a much lesser extent (about 100-fold selectivity), other phosphatases such as PP2B or PP7 while having virtually no effect on Ser/Thr phosphatases from the PPM (protein phosphatase $\mathrm{Mg}^{2+}$ - or $\mathrm{Mn}^{2+}$-dependent) family or the tyrosine phosphatases [20].

$\mathrm{OA}$ is the archetypal member of an entire class of remarkably distinct secondary metabolites from such disparate organisms as bacteria, blue-green algae, dinoflagellates, red algae, and even insects, that together comprise the "okadaic acid class of phosphatase inhibitors" [13]. Thus, the marine natural product OA is perhaps the most well-known member of a diverse array of secondary metabolites that have emerged as valuable probes for studying the roles of various cellular protein Ser/Thr phosphatases and has become one of the world's most widely used marine natural product in biological research.

Total synthesis of OA has been achieved and has allowed detailed topological and intermolecular recognition studies, largely through X-ray crystallography [13]. This information has then sparked 
considerable structure activity relationship studies directed toward the development of phosphatase-based therapeutics compounds [21] and has opened the door for the use of small molecule inhibitors to study the roles of sensitive protein phosphatases.

Apart from being quite a stable compound, OA is a fairly hydrophobic compound that can readily enter living cells, being able to cross the plasma membrane and block the dephosphorylation of proteins that are substrates for several protein kinases and constitutes, therefore, an excellent tool to analyze biological properties that are regulated through reversible protein phosphorylation [22,23].

The lack of sufficient specificity leads to relatively indiscriminant phosphatase inhibition though, and may simultaneously affect a variety of important cellular processes in addition to the targeted ones. Hence, we must be cautious to assign cellular functions to specific phosphatases based only on cellular effects observed after treatment with OA or its derivatives. Indeed to date, although a more selective inhibitor has been identified (fostriecin), OA remains the most widely used inhibitor in studies designed to provide insight into the biological actions of PP1 and PP2A.

Thus, under normal in vitro assay conditions, PP2A is completely inhibited by $1 \mathrm{nM} \mathrm{OA}$, while PP1 is unaffected at this concentration; however the use of this inhibitor to discriminate between the effects of the two target enzymes is not as powerful in living cells as it is on recombinant enzymes or in cell extracts. Cellular inhibition constants may be influenced by a number of factors, including intracellular concentrations of either competing target enzymes or effectors that may compete at the inhibitor binding site, cell permeability, half-life of compounds, etc. [24]. Since intracellular concentrations of PP2A and PP1 may vary between the different cell types, often lying within the range of $0.1-1.0 \mu \mathrm{M}$ [22], the right dose and time of treatment must be determined for each specific cell line [24,25].

Among the substrates already identified in different cell types, mounting evidence suggest that the cytoskeleton, a structure finely integrated to many cell functions, is particularly vulnerable to the toxic mechanisms induced by $\mathrm{OA}$ and related compounds, as altered phosphatase activity induced by pharmacological treatment with $\mathrm{OA}$ is accompanied by decreased cell adhesion and cytoskeletal reorganization [11,26]. On the other hand, it is noteworthy that OA and its derivatives do not bind phorbol ester receptors in cell membranes or activate protein kinase $\mathrm{C}$ in vitro. This lack of interaction with the phorbol ester receptor has led to the development of a new mechanistic pathway for tumor promotion [27,28].

Although conventional wisdom in the past 20 years has maintained that phosphatase inhibition is not only responsible for the intestinal effects of $\mathrm{OA}$ and derivatives, but also for their acute toxic effects, their tumor promoting activity and their neuronal toxicity, this mechanism of action has recently been questioned [18]. Despite this, OA's protein phosphatases' inhibition ability has been utilized in the development of sensitive assays for DSPs in shellfish [29,30].

\section{Using OA to Identify Highly Dynamic Phosphorylation Sites}

Phosphorylation, the reversible addition of a phosphate group to amino acid side chains of proteins, is a fundamental regulator of protein activity, stability, and molecular interactions. Most cellular processes such as inter- and intracellular signaling, protein synthesis, degradation, and apoptosis, rely on phosphorylation. This post-translational modification is thus involved in many diseases, rendering localization and assessment of extent of phosphorylation of major scientific interest. Therefore, the 
discovery and characterization of phosphoproteins, and the ability to identify specific phosphorylation sites, is of paramount importance for studying the molecular pathways that are regulated by reversible phosphorylation of proteins relevant in many cellular processes such as signal transduction, cell division and memory, among many others. Within this context, OA has emerged as an excellent tool for identifying and studying the myriad of events associated with the inhibition of protein Ser/Thr phosphatases and the reversible phosphorylation of proteins [22,23].

The ability of OA to inhibit PP2A/PP1 phosphatases has been used to facilitate the analysis of phosphorylated residues in many processes. Mainly, in cases of highly dynamic phosphorylation-dephosphorylation, OA treatment stops the high turnover phosphorylation allowing the detection of modified residues that could be difficult for identification under other circumstances. One case in point is that of some viral proteins, such as the human respiratory syncytial virus (HRSV) P protein [31]. This phosphorylated structural protein presents two types of phosphorylation sites, with phosphates added to a group of residues, a slower turnover is observed which can be detected in the absence of protein phosphatase inhibition. Whereas, inhibition of PP2A/PP1 with OA, increases the level of phosphorylation at some specific phosphosites, suggesting a more rapid turnover [32]. Actually, viral infection may also allow the high-turnover phosphorylation of proteins associated to the $\mathrm{P}$ proteins and the viral RNA polymerase complex [33,34]. Thus, OA treatment can be used to determine which amino acid residues incorporate high turnover phosphates during viral infection or other cellular processes. OA has in fact been shown to allow identification of cryptic phosphorylation sites in vivo that were not apparent in the absence of the inhibitor [35].

\section{OA-Induced Neurodegeneration}

OA was identified as a potent neurotoxin for cultured neuronal cells quite early on [36], as it is able to induce rapid time- and dose-dependent apoptotic changes in those cells [37]. Thus, different cell lines and primary neuronal cultures have been used to establish cellular models of OA-induced neurodegeneration, including human neuroblastoma cell lines [38,39], primary neuronal cultures [40-42] or even organotypic 3D cultures [43].

Not surprisingly, treatment of cultured cells with OA affects many different cellular pathways and numerous studies have been performed to clarify the various potential mechanisms of action or to look for ways to protect against OA-induced neurotoxicity. Thus, for instance, some authors have suggested that treatment of human neuroblastoma SH-SY5Y cells with OA may increase tau phosphorylation (see below) through sustained activation of the L-voltage-sensitive calcium channel [44] while others point to a role of GSK-3 in regulating tau phosphorylation and total tau levels [40]. On the other hand, different authors have involved calpain activation in OA toxicity in primary cortical neurons [45] and shown that pharmacological calpain inactivation can protect neurons against OA-induced neurodegeneration [46]. Another recent study worth mentioning shows that both $\alpha 7$ and $\beta 2 *$ nicotinic ACh receptors can afford neuroprotection against OA neurotoxicity in human neuroblastoma cells, independently of $\mathrm{Ca}^{++}$but involving the PI3K/Akt pathway [47]. Lastly, use of OA in cortical neurons has recently led to the identification of a novel signaling role of PP2A through the prolyl-isomerase Pin1 [48] which was proposed as a therapeutic target to reduce aberrant phosphorylation of 
neurofilament proteins in neurodegenerative disorders such as Alzheimer's disease (AD), Parkinson's disease, and amyotrophic lateral sclerosis.

Moreover, a recent work has used suppression subtractive hybridization in SH-SY5Y cells to identify genes that are differentially expressed after OA exposure [49]. A total of 247 subtracted clones (114 genes were up-regulated and 133 were down-regulated) which shared high homology with known genes were isolated, although only a handful were validated by quantitative real-time PCR. Most of these genes are involved in relevant cell functions such as metabolism, transport, translation, signal transduction and cell cycle, stressing the highly pleiotropic consequences of OA treatment.

Organotypic cultures made from slices of developing brain tissue preserve complex multi-cellular circumstances to a considerable extent - though not perfectly - and hence they have also been used to establish OA-induced neurodegeneration models. For instance, $400 \mu \mathrm{m}$-thick rat brain slices can be kept under metabolically active conditions in oxygenated $\left(95 \% \mathrm{O}_{2}, 5 \% \mathrm{CO}_{2}\right)$ artificial cerebrospinal fluid (CSF) and treated with $1.0 \mu \mathrm{M}$ OA for $1 \mathrm{~h}$. Under these conditions, PP2A activity was shown to decrease up to a third of the vehicle-treated control slices, while activities of PP1 and PP2B were not affected [50]. A dramatic increase in the phosphorylation/activation of ERK1/2, MEK1/2, and p70 S6 kinase was observed in the OA-treated slices both by immunohistochemically and by Western blots using phosphorylation-dependent antibodies against these kinases. Furthermore, treatment of $6 \mu \mathrm{m}$ sections of the OA-treated slices with purified PP2A reversed the phosphorylation/activation of these kinases.

In addition, OA also shows neurotoxicity in vivo. In an attempt to produce an animal model of AD-like neurofibrillary degeneration, OA was injected into the cerebral cortex of adult sheep [51], leading to the appearance of Alz50 immunoreactive dystrophic neurites. Later on, OA injection in rat hippocampus was used to assess its neurotoxicity in vivo [52,53], and shown to induce dose-dependent damage, including neuronal death, loss of MAP2 immunostaining and increased expression of heat shock proteins. Numerous studies have since then shown that when injected into the brains of rodents, OA induces neuronal damage and neuropathological changes reminiscent of those seen in Alzheimer's disease, including cognitive deficits such as memory impairment, as well as increased astrogliosis, oxidative stress, and neuronal death [54-57]. Since PP2A activity has been shown to be decreased in the brains of patients with $\mathrm{AD}$ [58], in vivo use of OA has also been revealed as an excellent way to understand diseases accompanied by protein hyperphosphorylation and cognitive deficits [38], as it is believed that protein hyperphosphorylation is due to inhibition of phosphatases in vivo and induces neuronal stress and subsequent neurodegeneration.

As noted below, intracerebral injection of OA causes tau hyperphosphorylation, formation of neurofibrillary tangles and deposits of $\beta$-amyloid, together with memory loss and neurodegeneration. It has been therefore suggested that intracerebral injection of OA, through its ability to inhibit protein phosphatases, would provide a useful model of Alzheimer's disease [59].

\section{Effects of OA on Tau Phosphorylation}

As already mentioned, changes in the brain activity of protein phosphatases have been implicated in the pathogenesis of neurodegenerative diseases such as Alzheimer's disease (AD) [60]. AD is a neurodegenerative disorder characterized by progressive memory loss and cognitive impairment while constituting the most common form of dementia among the elderly. The brains of patients suffering 
AD present the two classical hallmark histopathological lesions already described by Alois Alzheimer over a century ago, the extracellular "senile plaques" consisting of $\beta$-amyloid (A $\beta$ ) peptide, and intracellular neurofibrillary "tangles" (NFT) made up of hyperphosphorylated tau protein [61].

Tau protein is a microtubule-associated protein that in normal physiological conditions binds to and regulates assembly, dynamic behavior, and spatial organization of microtubules [62,63]. Within neurons, tau is predominantly found in axons as a highly soluble phosphoprotein where it also regulates the axonal transport of organelles, including mitochondria [64]. Tau is primarily, though not exclusively, a neuronal protein encoded by a single gene but with six major isoforms derived by alternative splicing $[65,66]$. Upon abnormal phosphorylation, the microtubule-associated protein tau reduces its affinity for and dissociates from microtubules. In $\mathrm{AD}$ brains, tau accumulates in the neuronal perikarya and processes as paired helical filaments (PHF) [67]. It has been suggested that at the single-cell level the defects start with a modification of tau by phosphorylation, resulting in a destabilization of microtubules giving rise to a "pre-tangle" stage. After this stage, the destabilization of microtubules leads to loss of dendritic microtubules and synapses, plasma membrane degeneration, and eventually cell death [68]. Furthermore, soluble abnormally phosphorylated tau can sequester both normal tau and HMW-MAPs and disassemble microtubules which most likely will also have implications for microtubule function $[69,70]$.

In addition to $\mathrm{AD}$, a number of other neurodegenerative disease present prominent tau pathology in the Central Nervous System (CNS), predominantly within the neuronal compartment, but also within glial cells. Because of this shared histopathological feature, they are referred collectively as tauopathies [71]. In tauopathies, the intracellular soluble tau forms abnormal, fibrillar structures of aggregated, hyperphosphorylated, and ubiquinated tau, which are associated with synaptic and neuronal loss. The occurrence of fibrillar tau inclusions in tauopathies strongly supports a key role in the observed clinical symptoms and pathology.

Phospho-tau may be toxic inside neurons of the dentate gyrus [72], although inherent toxicity of phosphorylated tau has been a matter of debate [73]. Once neuronal degeneration takes place, intracellular tau is released to the extracellular space and can be found in the cerebrospinal fluid [74], but the possibility of tau being released by exocytosis has also received some attention recently $[41,75]$. There are up to 80 potential phosphorylation sites in the largest tau molecule, most of them located at the proline-rich and $C$-terminal regions [76] and around 40 of them have been shown to be actually phosphorylated in PHF-tau [77,78]. However, the relative importance of specific individual phosphorylation sites or groups for tau function and/or pathogenesis remains to be firmly established. In tauopathies, including $\mathrm{AD}$, tau abnormalities - whether they are due to mutations in the tau gene or an altered 4R:3R tau ratio-cause brain deposition of highly phosphorylated tau in an aberrant conformation [79].

Hyperphosphorylation of tau has been suggested to be caused by an imbalance between kinase and phosphatase activities within the neurons during the development of Alzheimer's disease [60,80,81]. We and others have shown many years ago that OA can be used to increase tau phosphorylation in cultured cells $[82,83]$ and have used it, in combination with kinase inhibitors, as a tool to identify protein kinases responsible for phosphorylating specific residues [24].

Earlier studies have shown that a similar pattern of tau hyperphosphorylation than that observed in AD brains, including AD-related phosphoepitopes recognized by specific antibodies, can be obtained 
in cultured cells after OA treatment [82] and also in vivo after OA injection or microinfusion in rat hippocampus [38]. This increase in tau phosphorylation was believed to be a consequence of inhibiting PP2A since this enzyme is predominantly responsible for the dephosphorylation of this protein [84].

Hyperphosphorylation of tau at several abnormal hyperphosphorylation sites, as seen in AD brain, can be observed in OA-treated brain slices [50], as it has been suggested that the decrease in PP2A activity in $\mathrm{AD}$ brain may cause the activation of ERK1/2, MEK1/2, and p70 S6 kinase, and the abnormal hyperphosphorylation of tau, both via increased phosphorylation and decreased dephosphorylation. Organotypic cultures of brain slices have also been used to explore the effect of acute energy crisis on tau phosphorylation and the underlying mechanisms [85]. Tau was, unexpectedly, significantly dephosphorylated at different phosphoepitopes by acute anoxia for $30 \mathrm{~min}$ or 120 min whereas the activity of PP2A and the level of dephosphorylated PP2A catalytic subunit at residue Tyr307 were simultaneously increased and the active forms of ERK1/2 and JNK1/2 were decreased under anoxic incubation. Treatment of slices with $0.75 \mu \mathrm{M}$ OA completely prevented tau from acute anoxia-induced dephosphorylation and restored the active forms of ERK $1 / 2$ and JNK1/2 to the control level. Finally, some studies have shown inhibition of PP1 and PP2A after intracerebral injection of OA into rat brains [53].

As already discussed, phosphorylation at specific sites can affect tau physiological functions, including its role in binding to and stabilizing the neuronal cytoskeleton. Tau aberrant phosphorylation could render it susceptible to potentially pathogenic alterations, including conformational changes, proteolytic cleavage and aggregation. While strategies that reduce tau phosphorylation in transgenic models of disease have been promising, our understanding of the mechanisms through which tau becomes abnormally phosphorylated in disease is lacking and thus OA will surely remain as having a key role as a tool to gain further insight into tau phosphorylation events critical to the process of neurodegeneration. As a sample, OA has been used by the pharma industry to set up cell-based primary screening assays to look for inhibitors of tau phosphorylation at specific sites such as Ser422 [86]. Another study used human neuroblastoma SH-SY5Y cells to establish a novel cell-based three-dimensional tauopathy model that showed advanced characteristics of matured neurons in comparison to monolayer cultures, without the need of artificial differentiation promoting agents and in which the neurodegenerative effects could be analyzed in real time with high sensitivity using a microcavity array-based impedance spectroscopy measurement system [87]. This model uses OA to induce tau hyperphosphorylation in specific AD sites and neurodegeneration and has been proposed as a high content analysis-based drug screening assay.

Interestingly, OA neurotoxicity features have been recently used to set up a novel experimental model for Alzheimer studies in which a gradient of OA is generated over a neurite network that has been created in a microfluidic device connecting two separated cell compartments [88]. This further underlines the usefulness of $\mathrm{OA}$ as a wonderful biochemical tool for in vitro cell-based and in vivo studies involving protein phosphorylation events.

\section{Conclusions}

As the prototypic and first recognized member of the "okadaic acid class" of phosphatase inhibitors, the marine natural product, OA, is arguably the most well-known member of a diverse array 
of secondary metabolites that have emerged as valuable probes for studying the roles of various cellular protein Ser/Thr phosphatases. We have briefly provided a historical perspective on the role that OA has played in stimulating a broad spectrum of modern, cutting-edge scientific research, as a consequence of its ability to inhibit an important group of protein Ser/Thr phosphatases. OA treatment stops high turnover phosphorylation events and allows the detection of phospho-epitope that may be difficult to identify under other circumstances. OA is already being employed in basic studies directed towards understanding such diverse human disease-related processes such as cancer, AIDS and other viral infections, inflammation, osteoporosis, Alzheimer's disease, and diabetes. OA has also been widely used to establish a variety of cellular and animal models of OA-induced neurodegeneration as treatment of cells or injection of the compound into the brain of rodents brings about several AD-like pathological characteristics. Phosphorylation at specific sites can influence the physiological functions of tau protein. While strategies that reduce tau phosphorylation in transgenic models of disease are promising, our understanding of the mechanisms through which tau becomes abnormally phosphorylated in disease is lacking. Thus, OA definitely remains a powerful tool in future studies aimed at identifying relevant phosphoepitopes and clarifying their role in many physiological and pathological processes.

\section{References}

1. Tachibana, K.; Scheuer, P.J.; Tsukitani, Y.; Kikuchi, K.; Vanengen, D.C.J.; Gopichand, Y.; Schmitz, F.J. Okadaic acid, a cyto-toxic polyether from 2 marine sponges of the genus Halichondria. J. Am. Chem. Soc. 1981, 103, 2469-2471.

2. Cembella, A. Occurrence of okadaic acid, a major diarrheic shellfish toxin, in natural populations of Dinophysis spp. from the eastern coast of North America. J. Appl. Phycol. 1990, 1, 307-310.

3. Dickey, R.W.; Bobzin, S.C.; Faulkner, D.J.; Bencsath, F.A.; Andrzejewski, D. Identification of okadaic acid from a Caribbean dinoflagellate, Prorocentrum concavum. Toxicon 1990, 28, 371-377.

4. Yasumoto, T.; Murata, M.; Oshima, Y.; Sano, M.; Matsumoto, G.K.; Clardy, J. Diarrheic shellfish toxin. Tetrahedron 1985, 41, 1019-1025.

5. Kumagai, M.; Yamagi, T.; Murata, M.; Yasumoto, T.; Kat, M.; Lassus, P.; Rodriguez-Vazquez, J.A. Okadaic acid as the causative toxin of diarrheic shellfish poisoning in Europe. Agric. Biol. Chem. 1986, 50, 2857-2863.

6. Pistocchi, R.; Guerrini, F.; Pezzolesi, L.; Riccardi, M.; Vanucci, S.; Ciminiello, P.; Del'Aversano, C.; Forino, M.; Fattorusso, E.; Tartaglione, L.; et al. Toxin levels and profiles in microalgae from the North-Western Adriatic Sea-15 years of studies on cultured species. Mar. Drugs 2012, 10, 140-162.

7. Edebo, L.; Lange, S.; Li, X.P.; Allenmark, S. Toxic mussels and okadaic acid induce rapid hypersecretion in the rat small intestine. APMIS 1988, 96, 1029-1035.

8. Ito, E.; Terao, K. Injury and recovery process of intestine caused by okadaic acid and related compounds. Nat. Toxins 1994, 2, 371-377.

9. Franchini, A.; Marchesini, E.; Poletti, R.; Ottaviani, E. Swiss mice CD1 fed on mussels contaminated by okadaic acid and yessotoxins: Effects on thymus and spleen. Eur. J. Histochem. 2005, 49, 73-82. 
10. Ito, E.; Yasumoto, T.; Takai, A.; Imanishi, S.; Harada, K. Investigation of the distribution and excretion of okadaic acid in mice using immunostaining method. Toxicon 2002, 40, 159-165.

11. Franchini, A.; Malagoli, D.; Ottaviani, E. Targets and effects of yessotoxin, okadaic acid and palytoxin: A differential review. Mar. Drugs 2010, 8, 658-677.

12. Berven, G.; Saetre, F.; Halvorsen, K.; Seglen, P.O. Effects of the diarrhetic shellfish toxin, okadaic acid, on cytoskeletal elements, viability and functionality of rat liver and intestinal cells. Toxicon 2001, 39, 349-362.

13. Dounay, A.B.; Forsyth, C.J. Okadaic acid: The archetypal serine/threonine protein phosphatase inhibitor. Curr. Med. Chem. 2002, 9, 1939-1980.

14. Suganuma, M.; Fujiki, H.; Suguri, H.; Yoshizawa, S.; Hirota, M.; Nakayasu, M.; Ojika, M.; Wakamatsu, K.; Yamada, K.; Sugimura, T. Okadaic acid: An additional non-phorbol-12-tetrade canoate-13-acetate-type tumor promoter. Proc. Natl. Acad. Sci. USA 1988, 85, 1768-1771.

15. Sontag, J.M.; Sontag, E. Regulation of cell adhesion by PP2A and SV40 small tumor antigen: An important link to cell transformation. Cell Mol. Life Sci. 2006, 63, 2979-2991.

16. Fujiki, H.; Suganuma, M. Carcinogenic aspects of protein phosphatase 1 and 2A inhibitors. Prog. Mol. Subcell. Biol. 2009, 46, 221-254.

17. Bialojan, C.; Takai, A. Inhibitory effect of a marine-sponge toxin, okadaic acid, on protein phosphatases. Specificity and kinetics. Biochem. J. 1988, 256, 283-290.

18. Munday, R. Is protein phosphatase inhibition responsible for the toxic effects of okadaic acid in animals? Toxins (Basel) 2013, 5, 267-285.

19. Cohen, P. Classification of protein-serine/threonine phosphatases: Identification and quantitation in cell extracts. Methods Enzymol. 1991, 201, 389-398.

20. Swingle, M.; Ni, L.; Honkanen, R.E. Small-molecule inhibitors of ser/thr protein phosphatases: Specificity, use and common forms of abuse. Methods Mol. Biol. 2007, 365, 23-38.

21. Sakoff, J.A.; McCluskey, A. Protein phosphatase inhibition: Structure based design. Towards new therapeutic agents. Curr. Pharm. Des. 2004, 10, 1139-1159.

22. Cohen, P.; Holmes, C.F.; Tsukitani, Y. Okadaic acid: A new probe for the study of cellular regulation. Trends Biochem. Sci. 1990, 15, 98-102.

23. Fernandez, J.J.; Candenas, M.L.; Souto, M.L.; Trujillo, M.M.; Norte, M. Okadaic acid, useful tool for studying cellular processes. Curr. Med. Chem. 2002, 9, 229-262.

24. Medina, M.; Garcia-Rocha, M.; Padilla, R.; Perez, M.; Montejo de Garcini, E.; Avila, J. Protein kinases involved in the phosphorylation of human tau protein in transfected COS-1 cells. Biochim. Biophys. Acta 1996, 1316, 43-50.

25. Medina, M.; Montejo de Garcini, E.; Avila, J. The role of tau phosphorylation in transfected COS-1 cells. Mol. Cell Biochem. 1995, 148, 79-88.

26. Vale, C.; Botana, L.M. Marine toxins and the cytoskeleton: Okadaic acid and dinophysistoxins. FEBS J. 2008, 275, 6060-6066.

27. Herschman, H.R.; Lim, R.W.; Brankow, D.W.; Fujiki, H. The tumor promoters 12-O-tetradecanoylphorbol-13-acetate and okadaic acid differ in toxicity, mitogenic activity and induction of gene expression. Carcinogenesis 1989, 10, 1495-1498. 
28. Sassa, T.; Richter, W.W.; Uda, N.; Suganuma, M.; Suguri, H.; Yoshizawa, S.; Hirota, M.; Fujiki, H. Apparent "activation" of protein kinases by okadaic acid class tumor promoters. Biochem. Biophys. Res. Commun. 1989, 159, 939-944.

29. Albano, C.; Ronzitti, G.; Rossini, A.M.; Callegari, F.; Rossini, G.P. The total activity of a mixture of okadaic acid-group compounds can be calculated by those of individual analogues in a phosphoprotein phosphatase 2A assay. Toxicon 2009, 53, 631-637.

30. Garibo, D.; Dàmaso, E.; Eixarch, H.; de la Iglesia, P.; Fernández-Tejedor, M.; Diogène, J.; Pazos, Y.; Campàs, M. Protein phosphatase inhibition assays for okadaic acid detection in shellfish: Matrix effects, applicability and comparison with LC-MS/MS analysis. Harmful Algae 2012, 19, 68-75.

31. Asenjo, A.; Villanueva, N. Regulated but not constitutive human respiratory syncytial virus (HRSV) P protein phosphorylation is essential for oligomerization. FEBS Lett. 2000, 467, 279-284.

32. Asenjo, A.; Rodriguez, L.; Villanueva, N. Determination of phosphorylated residues from human respiratory syncytial virus $\mathrm{P}$ protein that are dynamically dephosphorylated by cellular phosphatases: A possible role for serine 54. J. Gen. Virol. 2005, 86, 1109-1120.

33. Asenjo, A.; Calvo, E.; Villanueva, N. Phosphorylation of human respiratory syncytial virus $\mathrm{P}$ protein at threonine 108 controls its interaction with the M2-1 protein in the viral RNA polymerase complex. J. Gen. Virol. 2006, 87, 3637-3642.

34. Asenjo, A.; Gonzalez-Armas, J.C.; Villanueva, N. Phosphorylation of human respiratory syncytial virus $\mathrm{P}$ protein at serine 54 regulates viral uncoating. Virology 2008, 380, $26-33$.

35. Huber, J.L.; Huber, S.C. Site-specific serine phosphorylation of spinach leaf sucrose-phosphate synthase. Biochem. J. 1992, 283, 877-882.

36. Fernandez, M.T.; Zitko, V.; Gascon, S.; Novelli, A. The marine toxin okadaic acid is a potent neurotoxin for cultured cerebellar neurons. Life Sci. 1991, 49, 157-162.

37. Leira, F.; Alvarez, C.; Vieites, J.M.; Vieytes, M.R.; Botana, L.M. Characterization of distinct apoptotic changes induced by okadaic acid and yessotoxin in the BE(2)-M17 neuroblastoma cell line. Toxicol. In Vitro 2002, 16, 23-31.

38. Zhang, Z.; Simpkins, J.W. An okadaic acid-induced model of tauopathy and cognitive deficiency. Brain Res. 2010, 1359, 233-246.

39. Chen, Z.; Chen, B.; Xu, W.F.; Liu, R.F.; Yang, J.; Yu, C.X. Effects of PTEN inhibition on regulation of tau phosphorylation in an okadaic acid-induced neurodegeneration model. Int. J. Dev. Neurosci. 2012, 30, 411-419.

40. Martin, L.; Page, G.; Terro, F. Tau phosphorylation and neuronal apoptosis induced by the blockade of PP2A preferentially involve GSK3beta. Neurochem. Int. 2011, 59, 235-250.

41. Kim, S.M.; Yoon, S.Y.; Choi, J.E.; Park, J.S.; Choi, J.M.; Nguyen, T.; Kim, D.H. Activation of eukaryotic initiation factor-2 alpha-kinases in okadaic acid-treated neurons. Neuroscience $\mathbf{2 0 1 0}$, 169, 1831-1839.

42. Ho, Y.S.; Yang, X.; Lau, J.C.; Hung, C.H.; Wuwongse, S.; Zhang, Q.; Wang, J.; Baum, L.; So, K.F.; Chang, R.C. Endoplasmic reticulum stress induces tau pathology and forms a vicious cycle: Implication in Alzheimer's disease pathogenesis. J. Alzheimer's Dis. 2012, 28, 839-854. 
43. Krinke, D.; Jahnke, H.G.; Mack, T.G.; Hirche, A.; Striggow, F.; Robitzki, A.A. A novel organotypic tauopathy model on a new microcavity chip for bioelectronic label-free and real time monitoring. Biosens. Bioelectron. 2010, 26, 162-168.

44. Ekinci, F.J.; Ortiz, D.; Shea, T.B. Okadaic acid mediates tau phosphorylation via sustained activation of the L-voltage-sensitive calcium channel. Brain Res. Mol. Brain Res. 2003, 117, $145-151$.

45. Yoon, S.Y.; Choi, J.E.; Yoon, J.H.; Huh, J.W.; Kim, D.H. BACE inhibitor reduces APP-beta-C-terminal fragment accumulation in axonal swellings of okadaic acid-induced neurodegeneration. Neurobiol. Dis. 2006, 22, 435-444.

46. Yoon, S.Y.; Choi, J.E.; Ham, J.H.; Choe, H.; Lee, H.S.; Kim, D.H. zVLL-CHO at low concentrations acts as a calpain inhibitor to protect neurons against okadaic acid-induced neurodegeneration. Neurosci. Lett. 2012, 509, 33-38.

47. Del Barrio, L.; Martin-de-Saavedra, M.D.; Romero, A.; Parada, E.; Egea, J.; Avila, J.; McIntosh, J.M.; Wonnacott, S.; Lopez, M.G. Neurotoxicity induced by okadaic acid in the human neuroblastoma SH-SY5Y line can be differentially prevented by alpha7 and beta2* nicotinic stimulation. Toxicol. Sci. 2011, 123, 193-205.

48. Rudrabhatla, P.; Albers, W.; Pant, H.C. Peptidyl-prolyl isomerase 1 regulates protein phosphatase 2A-mediated topographic phosphorylation of neurofilament proteins. J. Neurosci. 2009, 29, 14869-14880.

49. Valdiglesias, V.; Fernandez-Tajes, J.; Pasaro, E.; Mendez, J.; Laffon, B. Identification of differentially expressed genes in SHSY5Y cells exposed to okadaic acid by suppression subtractive hybridization. BMC Genomics 2012, 13, 46.

50. Pei, J.J.; Gong, C.X.; An, W.L.; Winblad, B.; Cowburn, R.F.; Grundke-Iqbal, I.; Iqbal, K. Okadaic-acid-induced inhibition of protein phosphatase $2 \mathrm{~A}$ produces activation of mitogen-activated protein kinases ERK1/2, MEK1/2, and p70 S6, similar to that in Alzheimer's disease. Am. J. Pathol. 2003, 163, 845-858.

51. Nelson, P.T.; Saper, C.B. Injections of okadaic acid, but not beta-amyloid peptide, induce Alz-50 immunoreactive dystrophic neurites in the cerebral cortex of sheep. Neurosci. Lett. 1996, 208, 77-80.

52. Arias, C.; Becerra-Garcia, F.; Arrieta, I.; Tapia, R. The protein phosphatase inhibitor okadaic acid induces heat shock protein expression and neurodegeneration in rat hippocampus in vivo. Exp. Neurol. 1998, 153, 242-254.

53. Arendt, T.; Holzer, M.; Fruth, R.; Bruckner, M.K.; Gartner, U. Phosphorylation of tau, abeta-formation, and apoptosis after in vivo inhibition of PP-1 and PP-2A. Neurobiol. Aging 1998, 19, 3-13.

54. Tapia, R.; Pena, F.; Arias, C. Neurotoxic and synaptic effects of okadaic acid, an inhibitor of protein phosphatases. Neurochem. Res. 1999, 24, 1423-1430.

55. He, J.; Yamada, K.; Zou, L.B.; Nabeshima, T. Spatial memory deficit and neurodegeneration induced by the direct injection of okadaic acid into the hippocampus in rats. J. Neural Transm. 2001, 108, 1435-1443.

56. Kamat, P.K.; Tota, S.; Rai, S.; Shukla, R.; Ali, S.; Najmi, A.K.; Nath, C. Okadaic acid induced neurotoxicity leads to central cholinergic dysfunction in rats. Eur. J. Pharmacol. 2012, 690, 90-98. 
57. Costa, A.P.; Tramontina, A.C.; Biasibetti, R.; Batassini, C.; Lopes, M.W.; Wartchow, K.M.; Bernardi, C.; Tortorelli, L.S.; Leal, R.B.; Goncalves, C.A. Neuroglial alterations in rats submitted to the okadaic acid-induced model of dementia. Behav. Brain Res. 2012, 226, 420-427.

58. Zhou, X.W.; Gustafsson, J.A.; Tanila, H.; Bjorkdahl, C.; Liu, R.; Winblad, B.; Pei, J.J. Tau hyperphosphorylation correlates with reduced methylation of protein phosphatase 2A. Neurobiol. Dis. 2008, 31, 386-394.

59. Arendt, T.; Hanisch, F.; Holzer, M.; Bruckner, M.K. In vivo phosphorylation in the rat basal nucleus induces PHF-like and APP immunoreactivity. Neuroreport 1994, 5, 1397-1400.

60. Braithwaite, S.P.; Stock, J.B.; Lombroso, P.J.; Nairn, A.C. Protein phosphatases and Alzheimer's disease. Prog. Mol. Biol. Transl. Sci. 2012, 106, 343-379.

61. Selkoe, D.J. Alzheimer's disease is a synaptic failure. Science 2002, 298, 789-791.

62. Drechsel, D.N.; Hyman, A.A.; Cobb, M.H.; Kirschner, M.W. Modulation of the dynamic instability of tubulin assembly by the microtubule-associated protein tau. Mol. Biol. Cell 1992, 3, 1141-1154.

63. LoPresti, P.; Szuchet, S.; Papasozomenos, S.C.; Zinkowski, R.P.; Binder, L.I. Functional implications for the microtubule-associated protein tau: Localization in oligodendrocytes. Proc. Natl. Acad. Sci. USA 1995, 92, 10369-10373.

64. Ebneth, A.; Godemann, R.; Stamer, K.; Illenberger, S.; Trinczek, B.; Mandelkow, E. Overexpression of tau protein inhibits kinesin-dependent trafficking of vesicles, mitochondria, and endoplasmic reticulum: Implications for Alzheimer's disease. J. Cell Biol. 1998, 143, 777-794.

65. Goedert, M.; Spillantini, M.G.; Potier, M.C.; Ulrich, J.; Crowther, R.A. Cloning and sequencing of the cDNA encoding an isoform of microtubule-associated protein tau containing four tandem repeats: Differential expression of tau protein mRNAs in human brain. EMBOJ. 1989, 8, 393-399.

66. Lee, G.; Neve, R.L.; Kosik, K.S. The microtubule binding domain of tau protein. Neuron 1989, 2 , 1615-1624.

67. Ledesma, M.D.; Medina, M.; Avila, J. The in vitro formation of recombinant tau polymers: Effect of phosphorylation and glycation. Mol. Chem. Neuropathol. 1996, 27, 249-258.

68. Iqbal, K.; Liu, F.; Gong, C.X.; Alonso Adel, C.; Grundke-Iqbal, I. Mechanisms of tau-induced neurodegeneration. Acta Neuropathol. 2009, 118, 53-69.

69. Alonso, A.C.; Grundke-Iqbal, I.; Iqbal, K. Alzheimer's disease hyperphosphorylated tau sequesters normal tau into tangles of filaments and disassembles microtubules. Nat. Med. 1996, 2, 783-787.

70. Alonso, A.D.; Grundke-Iqbal, I.; Barra, H.S.; Iqbal, K. Abnormal phosphorylation of tau and the mechanism of Alzheimer neurofibrillary degeneration: Sequestration of microtubule-associated proteins 1 and 2 and the disassembly of microtubules by the abnormal tau. Proc. Natl. Acad. Sci. USA 1997, 94, 298-303.

71. Hernandez, F.; Avila, J. Tauopathies. Cell Mol. Life Sci. 2007, 64, 2219-2233.

72. Avila, J.; Leon-Espinosa, G.; Garcia, E.; Garcia-Escudero, V.; Hernandez, F.; Defelipe, J. Tau phosphorylation by GSK3 in different conditions. Int. J. Alzheimer's Dis. 2012, 2012, 578373.

73. Castellani, R.J.; Nunomura, A.; Lee, H.G.; Perry, G.; Smith, M.A. Phosphorylated tau: Toxic, protective, or none of the above. J. Alzheimer's Dis. 2008, 14, 377-383. 
74. Iqbal, K.; Flory, M.; Khatoon, S.; Soininen, H.; Pirttila, T.; Lehtovirta, M.; Alafuzoff, I.; Blennow, K.; Andreasen, N.; Vanmechelen, E.; et al. Subgroups of Alzheimer's disease based on cerebrospinal fluid molecular markers. Ann. Neurol. 2005, 58, 748-757.

75. Avila, J. Intracellular and extracellular tau. Front. Neurosci. 2010, 4, 49.

76. Hanger, D.P.; Anderton, B.H.; Noble, W. Tau phosphorylation: The therapeutic challenge for neurodegenerative disease. Trends Mol. Med. 2009, 15, 112-119.

77. Morishima-Kawashima, M.; Hasegawa, M.; Takio, K.; Suzuki, M.; Yoshida, H.; Watanabe, A.; Titani, K.; Ihara, Y. Hyperphosphorylation of tau in PHF. Neurobiol. Aging 1995, 16, 365-371.

78. Hanger, D.P.; Byers, H.L.; Wray, S.; Leung, K.Y.; Saxton, M.J.; Seereeram, A.; Reynolds, C.H.; Ward, M.A.; Anderton, B.H. Novel phosphorylation sites in tau from Alzheimer brain support a role for casein kinase 1 in disease pathogenesis. J. Biol. Chem. 2007, 282, 23645-23654.

79. Medina, M. Recent developments in tau-based therapeutics for neurodegenerative diseases. Recent Pat. CNS Drug Discov. 2011, 6, 20-30.

80. Lovestone, S.; Reynolds, C.H. The phosphorylation of tau: A critical stage in neurodevelopment and neurodegenerative processes. Neuroscience 1997, 78, 309-324.

81. Martin, L.; Latypova, X.; Wilson, C.M.; Magnaudeix, A.; Perrin, M.L.; Terro, F. Tau protein phosphatases in Alzheimer's disease: The leading role of PP2A. Ageing Res. Rev. 2013, 12, 39-49.

82. Caillet-Boudin, M.L.; Delacourte, A. Induction of a specific tau Alzheimer epitope in SY-5Y neuroblastoma cells. Neuroreport 1996, 8, 307-310.

83. Shea, T.B.; Fischer, I. Phosphatase inhibition in human neuroblastoma cells alters tau antigenicity and renders it incompetent to associate with exogenous microtubules. FEBS Lett. 1996, 380, 63-67.

84. Liu, F.; Grundke-Iqbal, I.; Iqbal, K.; Gong, C.X. Contributions of protein phosphatases PP1, PP2A, PP2B and PP5 to the regulation of tau phosphorylation. Eur. J. Neurosci. 2005, 22, 1942-1950.

85. Liu, R.; Pei, J.J.; Wang, X.C.; Zhou, X.W.; Tian, Q.; Winblad, B.; Wang, J.Z. Acute anoxia induces tau dephosphorylation in rat brain slices and its possible underlying mechanisms. J. Neurochem. 2005, 94, 1225-1234.

86. Grueninger, F.; Bohrmann, B.; Christensen, K.; Graf, M.; Roth, D.; Czech, C. Novel screening cascade identifies MKK4 as key kinase regulating Tau phosphorylation at Ser422. Mol. Cell Biochem. 2011, 357, 199-207.

87. Seidel, D.; Krinke, D.; Jahnke, H.G.; Hirche, A.; Kloss, D.; Mack, T.G.; Striggow, F.; Robitzki, A. Induced tauopathy in a novel 3D-culture model mediates neurodegenerative processes: A real-time study on biochips. PLoS One 2012, 7, e49150.

88. Kunze, A.; Meissner, R.; Brando, S.; Renaud, P. Co-pathological connected primary neurons in a microfluidic device for Alzheimer studies. Biotechnol. Bioeng. 2011, 108, 2241-2245.

(C) 2013 by the authors; licensee MDPI, Basel, Switzerland. This article is an open access article distributed under the terms and conditions of the Creative Commons Attribution license (http://creativecommons.org/licenses/by/3.0/). 